\title{
Liquefaction of kenaf (Hibiscus cannabinus L.) core for wood laminating adhesive.
}

\begin{abstract}
A study was carried out to produce polyurethane (PU) as a wood laminating adhesive from liquefied kenaf core (LKC) polyols by reacting it with toluene-2,4-diisocyanate (TDI) and 1,4-butanediol (BDO). The LKC polyurethane (LKCPU) adhesive has a molecular weight (MW) of 2666, viscosity of $5370 \mathrm{mPa} \mathrm{s}$, and solids content of $86.9 \%$. The average shear strength of the rubberwood (RW) bonded with LKCPU adhesive was $2.9 \mathrm{MPa}$. Most of the sheared specimens experienced a total adhesive failure. The formation of air bubbles through the liberation of carbon dioxide was observed to reduce the adhesive penetration and bonding strength which was obviously seen on the sheared specimens. The percentage of catalyst used can be varied based on the usage and working time needed. Nonetheless, the physical properties of LKCPU produced in this work had shown good potential as edge-bonding adhesive.
\end{abstract}

Keyword: Liquefaction; Polyurethane; Kenaf core; Wood laminating adhesive. 